\title{
The impact of an inpatient hospital admission on patients' physical functioning and quality of life in the oncology setting
}

\author{
Andrew Murnane ${ }^{* 1,2}$, Justin Keogh ${ }^{3,4,5}$, Fiona Magat ${ }^{3}$, Sonya Imbesi ${ }^{3}$, Marie Coulombe ${ }^{2}$, Sharni Patchell ${ }^{2}$, Allan \\ Abbott ${ }^{3,6}$ \\ ${ }^{1}$ ONTrac at Peter Mac, Peter MacCallum Cancer Centre, Melbourne, VIC, Australia \\ ${ }^{2}$ Physiotherapy Department, Peter MacCallum Cancer Centre, Melbourne, VIC, Australia \\ ${ }^{3}$ Faculty of Health Sciences and Medicine, Bond University, Gold Coast, QLD, Australia \\ ${ }^{4}$ Human Potential Centre, AUT University, Auckland, New Zealand \\ ${ }^{5}$ Cluster for Health Improvement, Faculty of Science, Health, Education and Engineering, University of the Sunshine Coast, \\ Sunshine Coast, Australia \\ ${ }^{6}$ Department of Medical and Health Sciences, Division of Physiotherapy, Faculty of Health Sciences, Linköping University, \\ Linköping, Sweden
}

Received: November 12, 2014

Accepted: April 15, 2015

Online Published: April 28, 2015

DOI: $10.5430 /$ jnep.v5n7p75

URL: http://dx.doi.org/10.5430/jnep.v5n7p75

\begin{abstract}
Objective: Cancer can affect an individual's level of physical function and health related quality of life (HRQoL). Those requiring hospital admission may be at risk of further decline during hospitalisation. The aim of this study was to investigate physical functioning and HRQoL of cancer patients on admission and over the course of their hospital admission.

Methods: A prospective observational study was undertaken on the inpatient wards of a specialist oncology hospital. Assessment measures were taken bi-weekly until discharge from hospital or if they became too unwell to continue. Functional outcome measures included timed-up and go test (TUG), 30 second sit to stand test (30SST), 30 second arm curl test and isometric muscle strength (30ACT). HRQoL was assessed via the EORTC-C30 and SF-8 and distress was measured using the Distress Thermometer.

Results: Fifty-five patients (28 males), mean age 64 years \pm 10.8 , with an average length of stay of 19 days participated in the study. Primary reasons for hospital admission included; symptom management (36\%) or delivery of cancer treatment (35\%). On hospital admission, the majority of patients scored worse than normative levels on the EORTC-C30 and SF-8. Similarly, 65\%, $69 \%$ and 35\% recorded below age norms for TUG, 30SST and 30ACT. Most measures showed a trend towards worsening during hospitalisation with up to $59 \%$ of patients experiencing $\geq 10 \%$ worsening over time. However, only role and social functioning $(p$ $<.05)$, as well as financial difficulty showed statistically significant worsening $(p<.05)$ during hospitalisation.

Conclusions: Participants demonstrated substantially reduced HRQoL and physical functioning at time of hospital admission which tended to worsen during hospitalisation. Despite this low level of function, very few received rehabilitation followup. Screening programs using HRQoL and functional assessment measures could be useful in identifying patients who are deconditioned or at risk of deconditioning and require specialised therapy to prevent declines in function and hospital readmissions.
\end{abstract}

Key Words: Inpatient hospital admission, Physical function, Health related quality of life, Cancer patient

*Correspondence: Andrew Murnane; Email: Andrew.Murnane@petermac.org; Address: Locked Bag 1 A’Beckett Street, Melbourne, VIC, Australia. 


\section{INTRODUCTION}

A cancer diagnosis impacts the individual, their families and the healthcare system. In Australia, the cost of cancer care in the health care system equates to $7 \%$ of all public health expenditure. ${ }^{[1]}$ Of this, approximately $80 \%$ is spent in hospital admissions. ${ }^{[1]}$ The average length of stay for cancer patients is 7.6 days, which accounted for a collective total of 2.31 million days in hospital in 2011. ${ }^{[2,3]}$ In Australia, men and women over the age of 60 years account for $75 \%$ and $65 \%$ of new cancer cases, respectively. ${ }^{[2,3]}$ This cohort also often present with a number of other co-morbidities including cardiovascular disease, type II diabetes, arthritis, hypertension and cognitive dysfunction. ${ }^{[4,5]}$ With an aging population and complexity of cancer treatment increasing, it is expected that demands for inpatient beds will continue to increase.

Aging associated physiological decline includes loss of skeletal muscles mass, muscle weakness, decreased flexibility and decreased bone density. ${ }^{[6]}$ Prolonged inpatient admissions may result in physical deconditioning and reduced quality of life due to inactivity in the ward environment and the associated social isolation from family, friends and support networks. ${ }^{[7]}$ Research on deconditioning has found that complete bed rest can result in marked decreases in isometric muscle strength and whole-body muscle mass, with each week of bed rest accounting for a $10 \%$ decrease in muscular strength $;{ }^{[7-10]}$ Fatigue is also commonly reported in cancer patients. ${ }^{[9,11,12]}$ For many individuals, a natural response to fatigue is to decrease physical activity levels, ultimately leading to decreased muscle strength, a reduction in cardiac output, decreases in functional residual lung capacity, sedentary habits and a decreased ability to perform activities of daily living. ${ }^{[7,8,13]}$ There are a lack of studies assessing changes in physical functioning and quality of life of cancer patients during a hospital admission. However one can hypothesise that for hospital admission due to cancer, associated inactivity may exacerbate physical deconditioning exceeding that of the normal age-related decline.

One third of older hospitalised patients regardless of a cancer diagnosis will experience continued functional decline following a hospitalisation and a remaining one fifth will have ongoing decline in function 3 months post discharge. ${ }^{[5]}$ Considering that cancer patients may already have decreased levels of physical functioning before hospital admission and are at risk of physical decline during and after hospitalisation, deconditioning can have major implications for cancer treatment outcomes, the ongoing health of the patient and healthcare expenditure. With better knowledge of patient physical function on hospital admission and the rate of decline during hospitalisation, medical and allied health professionals can implement specific assessments and interventions aimed at preventing patient frailty and improving cancer treatment outcomes. It is therefore important to investigate the effects that hospitalisation has on cancer patient's health related quality of life (HRQoL) and physical functioning.

The aim of this study was to investigate physical functioning and HRQoL of cancer patients on admission and over the course of their hospital admission. The specific objectives of the study were to determine those patients who undergo a worsening of $\geq 10 \%$ during their admission and the measures that are most sensitive to change over time.

\section{MeThODS}

\subsection{Design and setting}

A prospective observational study was performed at Peter MacCallum Cancer Centre, a large specialist cancer facility in East Melbourne, Australia. The study was approved by the local Human Research Ethics Committee (12/134L) and informed written consent was obtained from all patients.

\subsection{Patient population}

Inpatients from the wards at Peter MacCallum Cancer Centre across all tumour streams were invited to take part in the study during a 14 week period between January and February in 2013 and 2014. Patients were excluded if their treatment intent was palliative; English was not their first language; under the age of 18; had a musculoskeletal condition that precluded exercise testing; and those with a planned discharge within the next $48 \mathrm{hrs}$.

\subsection{Recruitment and assessment procedures}

Eligible patients were identified through the screening of the daily inpatient lists. Prior to approaching patients, approval was sought from the Nurse Unit Manager or Associate Nurse Unit Manager to ensure that each patient was suitable to approach and take part in the study. A member of the study team provided each potential participant verbal and written Information about the study as well as a Consent Form. Consenting patients were asked to complete data assessments twice per week until they were discharged from hospital or became too unwell to continue. Standard care at the institution was followed for all participants and all consenting patients were screened prior to undertaking assessment measures to ensure no adverse events (e.g., MET call, febrile, pain crisis) had occurred over the past 24 hours that would prohibit assessment for that day.

\subsection{Demographic and background characteristics}

Demographic and medical data collected from participant medical records and patient self-report included age, sex, histological type, cancer stage, body mass index (BMI), Eastern 
Cooperative Oncology Group Performance Status (ECOGPS), current length of stay, current reason for admission and treatment undertaken, falls in the past 12 months and mobility limitations. Comorbidities were scored with the Charlson Comorbidity Index. ${ }^{[14,15]}$

\subsection{Patient reported outcome measures}

Physical activity was measured via the Godin Leisure-Time Exercise Questionnaire (GLTEQ) a self-report questionnaire that assesses usual leisure time exercise habits in minutes over the past week. ${ }^{[16]}$ Patients levels of reported physical activity were compared with the World Health Organisation (WHO) physical activity guidelines and were classified as sufficient $\geq 150$ mins/week; insufficient 1-149mins/week; or sedentary 0min/week. ${ }^{[17]}$ The European Organisation for the Research and Treatment of Cancer questionnaire (EORTC QLQ-C30) was used to assess HRQoL over the previous week. ${ }^{[18]}$ The Short Form 8 (SF-8) was used to assess health status and levels of psychosocial distress were assessed with the Distress Thermometer. ${ }^{[19,20]}$

\subsection{Functional outcome measures}

Functional outcome measures were assessed twice a week. Anthropometric measurements included weight, height, BMI and left bicep and calf circumference. Participant's mobility and falls risk were assessed using the timed-up and go test (TUG). ${ }^{[21]}$ A Powertrack-II Commander 1500 hand-held dynamometer was used to measure strength of knee extensor, ankle dorsiflexor and shoulder abductor muscles. An isometric muscle contraction was assessed for each muscle group and the highest force achieved over a five second duration was recorded. Lower limb muscle endurance was assessed using the 30 second sit to stand test (30SST) and upper limb muscle endurance was assessed using 30 second arm curl test (30ACT). ${ }^{[22]}$

\subsection{Data analysis}

Patient demographic data was analysed with descriptive statistics. Means and standard deviations were reported for continuous data, while numbers and percentages were reported for categorical data. Linear mixed models were used to analyse longitudinal changes in quality of life and physical functioning measures during the participants' inpatient length of stay. Linear mixed models are well suited to the analysis of longitudinal data due to data attrition, which in this case is due to varying length of ward stay for each participant. Unstructured repeated covariance type was used for random effects modelling with time as a fixed factor. Pairwise main effects comparisons were analysed between baseline and the additional two follow-up measures in a time frame of a week. Sidak adjustment to the confidence intervals and significance values was used to account for multiple comparisons. The EORTC-C30 physical functioning, global functioning and fatigue subscale values along with 30SST, TUG, 30ACT and isometric muscle strength were dichotomised to analyse the proportion of patients with $\geq 10 \%$ reduction in longitudinal scores.

\section{RESULTS}

\subsection{Study profile}

Between January and February 2013 and 2014 (14 weeks total) 459 patients were screened, of whom 142 (31\%) were eligible and 126 patients were approached (see Figure 1). 55 patients consented to take part in the study, a response rate of $44 \%$. Main reasons for non-consent included; too tired to participate $\mathrm{n}=27(38 \%)$; not interested in research project $\mathrm{n}=20(28 \%)$; and physically not capable of undertaking assessment measures $n=12(17 \%)$. Number of assessment measures completed across time-points and reason for noncompletion can be seen in Figure 1.

\subsection{Participant characteristics}

Demographic and medical characteristics of study participants are summarised in Table 1 . The mean age of study participants was 64.2 years ( $\mathrm{SD}=10.8$ years), $51 \%$ were male and the majority of the participants had a diagnosis of a haematological cancer $(31 \%)$ or skin and gastrointestinal cancers (both with 20\%). The three primary reasons for hospital admission were for symptom management (36\%), to receive treatment e.g., chemotherapy and or radiotherapy (35\%) or for surgery $(29 \%)$. The mean minutes of physical activity prior to admission was 105 minutes per week. Patients had an average weight loss over the last 12 months of $5 \mathrm{~kg}$ and a mean Charlson Comorbidity Index value of 6 . A total of 26 participants $(48 \%)$ reported a mobility limitation and 12 participants $(22 \%)$ reported a fall in the past 12 months. The average length of hospital admission was 19 days.

\subsection{Patient reported outcomes}

The mean changes in HRQoL and self-report distress during their inpatient stay are presented in Table 2. Patients' admitted to hospital had substantially lower HRQoL then aged match normative means for cancer patients rated on the EORTC-C30. The baseline SF-8 physical functioning and mental health domain were low and below normative means, $90 \%$ and $57 \%$ of patients respectively. Of the 34 patients completing follow-up measures, up to $59 \%$ and $32 \%$ experienced $\mathrm{a} \geq 10 \%$ worsening of EORT-C30 and SF8 subscales respectively. A number of statistically significant differences were seen on subscales on the EORT-C30 over the course of the inpatient admission, including decreased role function and social function and increased financial difficulty $(<0.05)$. 


\subsection{Functional outcome measures}

Table 2 describes the longitudinal change in functional measures over time. At baseline, $65 \%(\mathrm{n}=35)$ of inpatients scored worse than matched normative means on the TUG, $69 \%(\mathrm{n}=37)$ scored worse on the 30SST and 35\% $(\mathrm{n}=$ $19)$ on the 30 ACT. A statistically significant improvement $(<0.01)$ was seen in TUG test time from baseline to follow up 1 , and $15 \%$ ( $n=5$ of 34 ) of patients worsened over the course of their hospital admission. Respectively there was a $\geq 10 \%$ decline for $44 \%$ ( $\mathrm{n}=15$ of 34 ) on 30SST scores and $41(n=14$ of 34$)$ on the 30ACT. No significant change was in in mean bilateral maximal isometric muscle force across the three tests (knee extension, ankle dorsiflexion and shoulder abduction). However when looking at individual data over time $32 \%-41 \%$ of inpatients experienced a significant deterioration over the course of their inpatient admission as classified as a change of $\geq 10 \%$. Similarly $44 \%$ ( $n=15$ of 34 ) had a worsening of ward laps walked during hospitalisation.

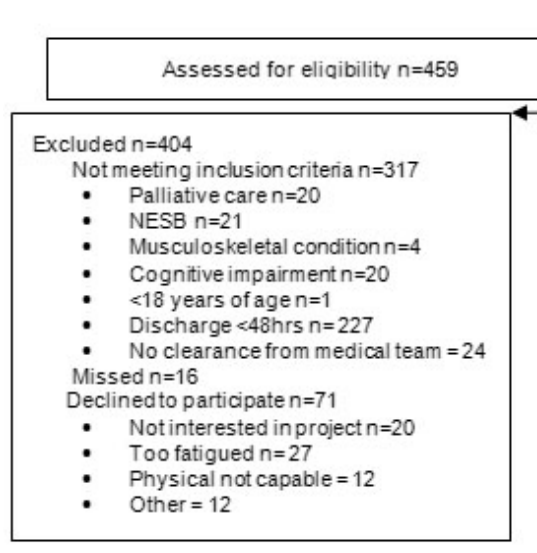

\section{Enrolment}
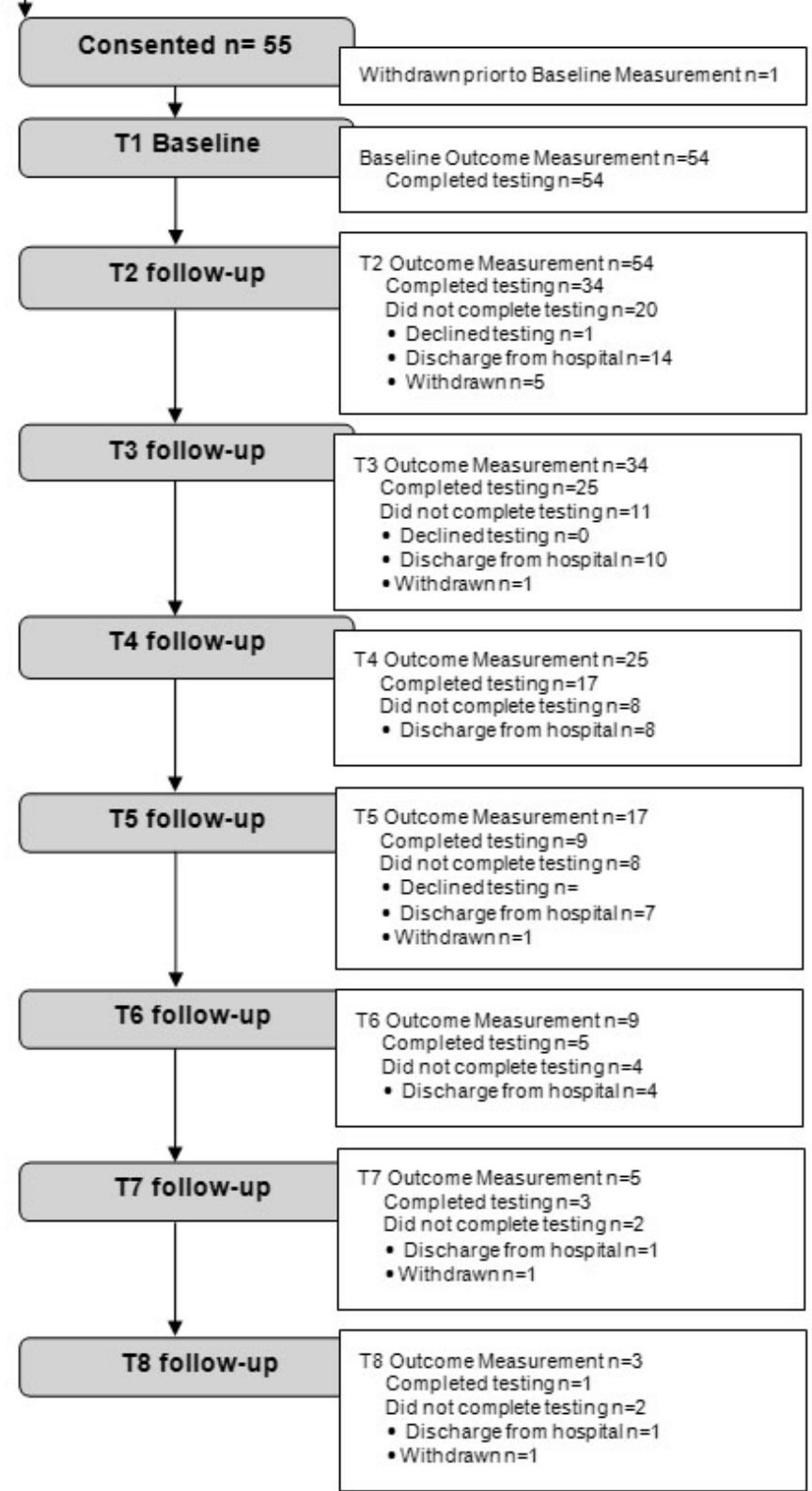

Figure 1. Consort diagram

Abbreviations: NESB, non-English speaking background. 
Table 1. Patient demographics

\begin{tabular}{|c|c|}
\hline Patient characteristics $^{\dagger}$ & Test group $(n=55)$ \\
\hline Female & $27(49.1)$ \\
\hline Male & $28(50.9)$ \\
\hline Age (yrs) & $64.2 \pm 10.8$ \\
\hline Body mass index $(\mathrm{kg} / \mathrm{m})$ & $25.8 \pm 5.3$ \\
\hline Weight loss in last 12 months (kg) & $5.3 \pm 5.1$ \\
\hline Amount of activity per week (mins) & $105 \pm 102$ \\
\hline Godin Leisure Time Exercise Questionnaire & $22.4 \pm 23.2$ \\
\hline Charlson Comorbidity Index & $6.2 \pm 2.6$ \\
\hline Distress thermometer & $4.9 \pm 3.2$ \\
\hline \multicolumn{2}{|l|}{ Cancer type } \\
\hline Breast & $4(7.3)$ \\
\hline Head and neck & $3(5.5)$ \\
\hline Haematological & $17(30.9)$ \\
\hline Gastrointestinal & $11(20)$ \\
\hline Sarcoma & $3(5.5)$ \\
\hline Lung & $4(7.3)$ \\
\hline Skin & $11(20)$ \\
\hline Urological & $2(3.6)$ \\
\hline \multicolumn{2}{|l|}{ Cancer stage } \\
\hline I & $3(5.5)$ \\
\hline II & $2(3.6)$ \\
\hline III & $11(20)$ \\
\hline IV & $21(38.2)$ \\
\hline Unknown & $18(32.7)$ \\
\hline \multicolumn{2}{|l|}{ Reason for ward admission } \\
\hline Surgery & $16(29.1)$ \\
\hline Radiotherapy/Chemotherapy & $19(34.5)$ \\
\hline Symptom management & $20(36.4)$ \\
\hline \multicolumn{2}{|l|}{ ECOG Performance status } \\
\hline Asymptomatic & $10(18.5)$ \\
\hline Symptomatic but completely ambulatory & $24(44.4)$ \\
\hline Symptomatic, $<50 \%$ in bed during the day & $13(24.1)$ \\
\hline Symptomatic, $>50 \%$ in bed, but not bedbound & $6(11.1)$ \\
\hline Bedbound & $1(1.9)$ \\
\hline Reported fall in last 12 months & $12(22.2)$ \\
\hline Reported Mobility Limitations & $26(48.2)$ \\
\hline Length of stay (days) & 18.7 \\
\hline \multicolumn{2}{|l|}{ Treatment Undergone* (multiple answer) } \\
\hline Palliative Radiotherapy & 5 \\
\hline High Dose Radiotherapy & 16 \\
\hline Chemotherapy & 38 \\
\hline Surgery & 37 \\
\hline Transplant & 6 \\
\hline No Treatment & 6 \\
\hline \multicolumn{2}{|l|}{ Distance walked during admission (meters) } \\
\hline Baseline & $338.4(n=49)$ \\
\hline Fourth Measure & $518.8(\mathrm{n}=17)$ \\
\hline
\end{tabular}

\section{Discussion}

To our knowledge, this is the first study which has attempted to monitor the physical functioning and quality of life of cancer patients during a hospital admission. Our results demonstrated that on presentation to hospital, physical status and HRQoL was well below aged match normative data for many participants. ${ }^{[22-24]}$ The participants also reported Published by Sciedu Press lower HRQoL when compared to a similar oncology population. ${ }^{[23]}$ Most measures showed a trend towards worsening during hospitalisation, but only EORTC-C30 role and social functioning and financial difficulty $(p<.05)$ showed a statistically significant improvement. TUG $(p<.01)$ was the only measure that showed a statistically significant improvement during hospitalisation however overall functional performance remained poor. This signifies the importance of monitoring patients with self-reported HRQoL and physical function tests to detect deterioration during hospital admission.

The inclusion of the TUG as an assessment measure was chosen as it is a commonly used screening tool to assist clinicians to identify patients at risk of falling. In 2012, Alexandre et al. found that elderly community-dwellers who recorded a TUG time equal or greater than 12.47 seconds were three times more at risk of falls than those who completed the TUG more quickly. ${ }^{[25]}$ Within our sample, 12 participants (35\%) recorded a TUG time greater than 12.47 seconds at time of discharge indicating a potential risk of fall in the community setting. Only half of the patients showing TUG, 30SST and 30ACT below aged matched norms at discharge were referred for ongoing rehabilitation either as an inpatient or outpatient in the community. Exercise interventions post discharge have been shown to improve patients QoL, physical functioning, increase engagement in social activities and decrease fatigue. ${ }^{[26-28]}$ Despite the known benefits of exercise on patient's fitness, these patients within our cohort remain at risk of further functional decline at home and or hospital readmission due to poor functional capacity and requires further review.

Muscle function is a strong predictor of cancer mortality, morbidity and HRQoL. ${ }^{[13,28,29]}$ Cancer patients who develop sarcopenia (a geriatric condition characterised by losses of muscle mass, strength and function) 12 months after a cancer diagnosis were associated with a poorer prognosis. ${ }^{[8]}$ On admission, participants in our study had low mean levels of lower (10-14 kg) and upper (8 kg) limb isometric strength. It was also apparent that $32 \%-38 \%$ of participants with repeated lower limb isometric strength measures displayed a decline $\geq 10 \%$ in lower limb strength. A similar proportion (41\%) of participants with repeated upper limb measures showed similar decline in upper limb strength. Lower limb and upper limb weakness has been shown to be associated with the risk of serious falls in older adults within the community. ${ }^{[30]}$ When combining isometric strength measures with TUG, 30CST and 30ACT data, illustrates the poor functional capacity of patients' diagnosed with cancer and the impact an inpatient hospital admission has on muscle strength and endurance. 
Table 2. Longitudinal change in quality of life and functional measures

\begin{tabular}{|c|c|c|c|c|c|c|}
\hline Measure & $\begin{array}{l}\text { Normative mean } \\
\text { data }\end{array}$ & $\begin{array}{l}\text { Baseline } \\
\text { Mean } \pm \text { SD } \\
(n=54)\end{array}$ & $\begin{array}{l}\text { Follow-up } 1 \\
\text { Mean difference } \\
\text { from baseline } \\
(95 \% \mathrm{CI})\end{array}$ & $\begin{array}{l}\text { Follow-up } 2 \\
\text { Mean difference } \\
\text { from baseline } \\
(95 \% \mathrm{CI})\end{array}$ & $\begin{array}{l}\% \text { (number) of } \\
\text { patients worse } \\
\text { than normative } \\
\text { data at } \\
\text { baseline }\end{array}$ & $\begin{array}{l}\% \text { (number) of } \\
\text { patients }>10 \% \\
\text { worsening during } \\
\text { hospitalisation } \\
(\mathrm{n}=34)\end{array}$ \\
\hline EORTC-C30 & (60-69 Years) & & & & & \\
\hline Global Health Status & 61.8 & $42.6 \pm 26.2$ & $-3.2(-13.5$ to 7.2$)$ & 11.1 (-2.9 to 25.3$)$ & $75(41)$ & $47(16)$ \\
\hline Physical Functioning & 76.3 & $62.2 \pm 29.5$ & $-6.0(-20.6$ to 8.7$)$ & $-6.4(-23.0$ to 10.2$)$ & $56(31)$ & $44(15)$ \\
\hline Role Functioning & 72.6 & $34.6 \pm 34.9$ & $-13.1(-25.1 \text { to }-1.2)^{*}$ & $-0.8(-16.7$ to 15.2$)$ & $84(46)$ & $56(19)$ \\
\hline Emotional Functioning & 71.8 & $70.2 \pm 25.6$ & $-0.4(-7.3$ to 6.4$)$ & $8.6(-1.1$ to 18.4$)$ & $46(25)$ & $17(6)$ \\
\hline Cognitive Functioning & 83.1 & $64.2 \pm 27.6$ & $4.1(-4.3$ to 12.4$)$ & $0.2(-21.2$ to 21.6$)$ & $55(30)$ & $27(9)$ \\
\hline Social Functioning & 76.4 & $41.1 \pm 38.1$ & $-4.9(-21.0$ to 11.3$)$ & $-15.0(-29.9 \text { to }-0.1)^{*}$ & $76(42)$ & $59(20)$ \\
\hline Fatigue & 34.1 & $61.5 \pm 26.9$ & -0.4 (-9.9 to 9.1$)$ & $-0.6(-13.6$ to 12.3$)$ & $75(41)$ & $56(19)$ \\
\hline Nausea & 8.7 & $28.1 \pm 31.9$ & $0.3(-8.7$ to 9.4$)$ & $-7.7(-20.3$ to 4.9$)$ & $58(32)$ & $47(16)$ \\
\hline Pain & 26.4 & $54.0 \pm 37.3$ & $-10.8(-23.5$ to 1.8$)$ & $-15.5(-42.5$ to 11.5$)$ & $67(37)$ & $29(10)$ \\
\hline Dyspnoea & 22.1 & $32.1 \pm 34.3$ & -1.1 (-11.8 to 9.7$)$ & $-15.2(-32.6$ to 2.2$)$ & $60(33)$ & $27(9)$ \\
\hline Insomnia & 28.6 & $39.5 \pm 33.1$ & 3.1 (-13.9 to 20.2$)$ & 5.8 (-17.6 to 29.2$)$ & $71(39)$ & 38 (13) \\
\hline Appetite & 21.0 & $50.6 \pm 39.8$ & $-6.5(-19.6$ to 6.5$)$ & $-9.3(-39.9$ to 21.4$)$ & $27(15)$ & $27(9)$ \\
\hline Constipation & 17.7 & $27.8 \pm 35.3$ & $-3.0(-17.5$ to 11.6$)$ & $-12.2(-25.0$ to 0.6$)$ & $47(26)$ & $50(17)$ \\
\hline Diarrhoea & 9.2 & $30.2 \pm 37.4$ & $8.6(-10.3$ to 27.4$)$ & $-5.0(-27.3$ to 17.3$)$ & $47(26)$ & $47(16)$ \\
\hline Financial difficulty & 13.8 & $26.5 \pm 32.6$ & -0.7 (-8.0 to 6.7$)$ & $12.3(0.1 \text { to } 24.5)^{*}$ & $47(26)$ & $53(18)$ \\
\hline \multicolumn{7}{|l|}{ SF-8 } \\
\hline Physical Functioning & 49.6 & $25.3 \pm 14.6$ & $2.7(-2.5$ to 8.0$)$ & 3.0 (-6.8 to 12.8$)$ & $90(49)$ & $32(11)$ \\
\hline Mental Health & 42.1 & $38.4 \pm 14.8$ & $2.1(-5.5$ to 9.7$)$ & $-2.4(-12.4$ to 7.6$)$ & $57(31)$ & $32(11)$ \\
\hline \multicolumn{7}{|l|}{ Mean Bilateral Maximal } \\
\hline \multicolumn{7}{|l|}{ Isometric Muscle Force (kg) } \\
\hline Knee Extension & - & $14.2 \pm 4.5$ & $-0.1(-1.4$ to 1.7$)$ & $-0.6(-2.0$ to 0.7$)$ & - & $38(13)$ \\
\hline Ankle Dorsiflexion & - & $10.4 \pm 3.4$ & $1.9(-1.6$ to 5.4$)$ & $2.0(-0.1$ to 4.0$)$ & - & $32(11)$ \\
\hline Shoulder Abduction & - & $8.2 \pm 3.8$ & $-0.1(-0.8$ to 0.7$)$ & $0.7(-0.3$ to 1.8$)$ & - & $41(14)$ \\
\hline Daily Wards Laps (number) & - & $5.6 \pm 7.2$ & $0.7(-1.7$ to 3.0$)$ & $1.0(-1.6$ to 3.7$)$ & - & $44(15)$ \\
\hline \multicolumn{7}{|l|}{ Functional measures } \\
\hline Timed up and go (sec) & 8.1 & $18.4 \pm 12.7$ & $-5.0(-8.7 \text { to }-1.4)^{* *}$ & $0.5(-11.8$ to 12.7$)$ & $65(35)$ & $15(5)$ \\
\hline 30-Second chair sit to stands & $\mathrm{M}:>12 ; \mathrm{F}:>10$ & $6.7 \pm 6.5$ & $-1.2(-2.6$ to 0.2$)$ & $-0.1(-1.7$ to 1.5$)$ & $69(37)$ & $44(15)$ \\
\hline 30-Second Arm Curl (reps) & M: 15-21; F: 12-18 & $8.2 \pm 3.8$ & $-0.2(-2.5$ to 2.1$)$ & $3.3(0.5 \text { to } 6.1)^{*}$ & 35 (19) & $41(14)$ \\
\hline
\end{tabular}

The EORTC-C30 measures cancer patients physical, psychological and social functioning. The questionnaire is composed of 5 multi item scales (physical, role, social, emotional and cognitive functioning), three symptom scales (fatigue, nausea and pain) and 6 single items (dyspnea, insomnia, appetite, constipation, diarrhea and financial difficulty). It also provides an overall assessment of the participants QOL (the global health status). Some significant changes in HRQoL were seen during the course of the hospital admission and when compared to aged match norms, participants at admission were well below normative data. ${ }^{[23]}$ At discharge patients remained below normative data on 4 of the 5 multi item scales (with emotional functioning being the only one above). Global health status showed a small improvement over time but remained well below normative values. A similar picture was seen in relation to the SF- 8 with no statistically significant change over time. However, both the physical functioning (90\%) and mental health $(57 \%)$ of the patients as assessed by the SF- 8 were below matched means.

When looking at the 3 symptom scales and 6 single items on the EORTC-C30, it was apparent that patients within our sample were much worse than aged match means. $37 \%$ of participants were admitted to hospital for symptom management so it is not surprising that their scores were significantly worse than the aged match mean. The results highlight the good job health professionals do in managing the patient's symptoms with the majority of the symptoms, including nausea, pain, dysponea and poor appetite declining while in hospital. However self-reported fatigue levels remained high with no real change over time and were persistent during the course of hospital admission. This may account for lower levels of physical activity during the course of the participants' admission and may in turn impact on one's ability to carry out activities of daily living and contribute to a loss of independence. ${ }^{[31]}$

This study encourages a review of current inpatient oncology screening processes to identify patients most at risk of further functional decline. The TUG test and 30SST are functional outcome measures that are easy to conduct on ward and are validated with age matched normative data. Early identification of patients most at risk of adverse events not only allows for timely implementation of interventions but also 
may reduce the risk for patient dependence, re-admission or fatality due to decreased function. Introducing functional assessment measures along with a quality of life assessment into routine nursing or allied health practice within acute oncology wards warrants further investigation.

A limitation of the current study is the small cohort of participants. Difficulties were seen with recruitment of participants for the current study. As the Peter MacCallum Cancer Centre is an acute hospital many patients were discharged in less than 48 hours, which did not permit enough time between follow up measurements. Participants at commencement of this study present with functional decline and report a lower HRQoL during the initial days of their admission, which possibly leaves a small window of further decline. Recent studies have found that older individuals who were previously independent prior to hospital admission were at higher risk of functional decline when compared to their peers who were dependent prior to admission. ${ }^{[5]}$ The main reason for eligible patients declining to take part in the study was due to feeling overwhelmed or that they had too much to deal with; these patients would potentially report lower HRQoL than what has been noted in the current study. Many consenting participants declined follow up measures at certain time points due to fatigue, pain, distress, "too much going on at the moment" or uncertainty of their medical plan.

Despite these methodological limitations, this is one of the first studies that aimed to identify patients at risk of inpatient deconditioning using both HRQoL and functional measures.
Strengths of the study include the use of HRQoL measures that are validated within a cancer population and the use of functional outcome measures with gender and age matched normative data. The study also investigated the rate of decline in these outcomes across a broad range of cancer diagnoses undergoing a wide range of treatments. Knowing the proportion of patients at risk of functional decline and having appropriate screening tools to detect these patients has significant clinical implications in the prevention and reduction of functional decline and associated risks. It contributes to the knowledge of the literature in regards to oncology patients' function. Future research is needed to investigate exercise interventions that will aid in preventing decline in this patient demographic.

\section{Conclusion}

Participants demonstrated substantially reduced HRQoL and physical functioning at time of hospital admission which tended to worsen during hospitalisation. Despite this low level of function, very few received rehabilitation follow-up. Screening programs using HRQoL and functional assessment measures could be useful in identifying patients who are deconditioned or at risk of deconditioning and require specialised therapy to prevent declines in function and hospital re-admissions.

\section{CONFLICTS OF INTEREST DISCLOSURE}

The authors declare that there is no conflict of interest statement.

\section{REFERENCES}

[1] Australian Institute of Health and Welfare. Health system expenditure on cancer and other neoplasms in Australia: 2008-2009. In Cancer (Ed.). Canberra; 2013.

[2] Australian Institute of Health and Welfare. Cancer incidence projections: Australia, 2011 to 2020. Cancer Series no. 66. Cat. No. CAN 62. Canberra: AIHW. 2012.

[3] Australian Institute of Health and Welfare \& Australasian Association of Cancer Registries. Cancer in Australia: an overview, 2012. Cancer series no. 74. Cat. no. CAN 70. Canberra: AIHW; 2012.

[4] Cronenwett L, Sherwood G, Barnsteiner J, et al. Quality and safety education for nurses; Chapter 11: Reducing functional decline in hospitalized elderly. Nursing Outlook. 2007; 55(3): 122131. PMid:17524799 http://dx.doi.org/10.1016/j.outlook .2007 .02 .006

[5] Wu HY, Sahadevan S, Ding YY. Factors associated with functional decline of hospitalised older persons following discharge from an acute geriatric unit. Annals of the Academy of Medicine, Singapore. 2006; 35(1): 17. PMid:16470269

[6] Balducci L. Treatment of cancer in the older aged person. Mediterranean Journal of Hematology and Infectious Diseases. 2010; 2(2): e2010029. PMid:21415975 http://dx.doi.org/10.4084/mjh id. 2010.029

[7] Gillis TA, Grahma HF. Watch for deconditioning in cancer patients and prescribed exercise. The Journal of Supportive Oncology. 2007; 5(2): 94-95.

[8] Christensen JF, Jones LW, Andersen JL, et al. Muscle dysfunction in cancer patients. Annals of Oncology. 2014; 25(5): 947-58. http://dx.doi.org/10.1093/annonc/mdt551

[9] Packel L, Claghorn K, Dekerlegand J. Cancer- related fatigue and deconditioning a program evaluation. Journal of Rehabilitation Oncology. 2006; 24(2): 3-8.

[10] Crannell C, Stone E. Bedside physical therapy project to prevent deconditioning in hospitalized patients with cancer. Oncology Nursing Forum. 2008; 35(3): 343-345. PMid:18467285 http://dx.doi.o $\mathrm{rg} / 10.1188 / 08.0 \mathrm{NF} .343-345$

[11] Portenoy RK, Itri LM. Cancer-related fatigue: guidelines for evaluation and management. Oncologist. 1999; 4(1): 1-10. PMid:10337366

[12] Brown L, Kroenke K. Cancer-related fatigue and its associations with depression and anxiety: a systematic review. Psychosomatics. 2009; 50(5): 440-447. http://dx.doi.org/10.1016/S0033-3 182 (09) $70835-7$ 
[13] Jones L, Haykowsky M, Swartz J, et al. Early breast cancer therapy, cardiovascular injury and the "multiple-hit" hypothesis. Journal of the American College of Cardiology. 2007; 50(15). http: //dx.doi.org/10.1016/j.jacc.2007.06.037

[14] Charlson ME, Pompei P, Ales KL, et al. A new method of classifying prognostic comorbidity in longitudinal studies: development and validation. Journal of chronic diseases. 1987; 40(5): 373-383 http://dx.doi.org/10.1016/0021-9681(87)90171-8

[15] Quan H, Li B, Couris CM, et al. Updating and validating the Charlson comorbidity index and score for risk adjustment in hospital discharge abstracts using data from 6 countries. American Journal of Epidemiology. 2011; 173(6): 676-682. PMid:21330339 http://dx.doi.org/10.1093/aje/kwq433

[16] Godin G, Shephard R. A simple method to assess exercise behaviour in the community. Canadian Journal of Applied Sport Science. 1985; 10: 141-146. PMid:4053261

[17] WHO. Global recommendations on physical activity for health. Geneva: World Health Organization; 1-58. ISBN: 9789241599979. 2010.

[18] Aaronson NK, et al. The European Organization for Research and Treatment of Cancer QLQ-C30: a quality-of-life instrument for use in international clinical trials in oncology. J Natl Cancer Inst. 1993; 85(5): 365-76. http://dx.doi.org/10.1093/jnci/85.5.365

[19] Ware J, Kosinski M, Dewey J, et al. How to score and interpret singleitem health status measures: a manual for user of the SF-8. Lincoin, RI: Quality-Metric Incorporated. 2001.

[20] Jacobsen PB, Donovan KA, Trask PC, et al. Screening for psychological distress in ambulatory cancer patients. Cancer. 2005; 103 1494-1502. PMid:15726544 http://dx.doi.org/10.1002/cnc r. 20940

[21] Podsiadlo D, Richardson S. The timed "Up \& Go": a test of basic functional mobility for frail elderly persons. Journal American Geriatric Society. 1991; 39: 142-148. PMid:1991946

[22] Rikli, Jones. Senior fitness test manual. (Champaign, IL: Human Kinetics). 2001; 61, 63, 65.
[23] Scott N, Fayers P, Aaronson N, et al. EORTC QLQC30 Reference Values. European Organisation for Research and Treatment of Cancer. 2008. Available from: http://groups. eortc.be/qol/sites/default/files/ img/newsletter/reference_values_manual2008.pdf

[24] Crouchley K, Daly A. Chronic Disease and Quality of Life in Western Australia. Department of Health, Western Australia. 2007. PMid:17612423

[25] Alexandre TS, Meira DM, Rico NC, et al. Accuracy of Timed Up and Go Test for screening risk of falls among community-dwelling elderly. Brazilian Journal of Physical Therapy. 2012; 16(5): 381-388. http://dx.doi.org/10.1590/S1413-35552012005000041

[26] Demark-Wahnefried W, Pinto BM, Gritz ER. Promoting health and physical function among cancer survivors: potential for prevention and questions that remain. Journal of Clinical Oncology. 2006; 24(32): 5125-5131. PMid:17093274 http://dx.doi.org/10.12 00/JC0.2006.06.6175

[27] Dimeo FC. Effects of exercise on cancer-related fatigue. Cancer. 2001; 92: 1689-93. http://dx.doi.org/10.1002/1097-014 2 (20010915) 92:6+<1689: :AID-CNCR1498>3. 0. CO;2-H

[28] Hayes SC, et al. Australian Association for Exercise and Sport Science position stand: optimising cancer outcomes through exercise. J Sci Med Sport. 2009; 12(4): 428-34. PMid:19428291 http://dx.doi.org/10.1016/j.jsams.2009.03.002

[29] Maddocks M, Mockett S, Wilcock A. Is exercise an acceptable and practical therapy for people with or cured of cancer? A systematic review. Cancer Treat Rev. 2009; 35(4): 383-90. PMid:19131171 http://dx.doi.org/10.1016/j.ctrv.2008.11.008

[30] Moreland JD, Richardson JA, Goldsmith CH, et al. Muscle weakness and falls in older adults: a systematic review and meta-analysis. Journal of the American Geriatrics Society. 2004; 52(7): 11211129. PMid:15209650 http://dx.doi.org/10.1111/j.1532-5 415.2004.52310.x

[31] Blaney J, Lowe-Strong A, Rankin J, et al. The cancer rehabilitation journey: barriers to and facilitators of exercise among patients with cancer-related fatigue. Physical therapy. 2010; 90(8): 1135-1147. PMid:20558566 http://dx.doi.org/10.2522/pt j . 20090278 